Acta Crystallographica Section C

Crystal Structure

Communications

ISSN 0108-2701

\section{2,3-Dimethoxy-10-oxostrychnidinium 2-(2,4,6-trinitroanilino)benzoate monohydrate: a 1:1 proton-transfer salt of brucine with o-picramino- benzoic acid}

\section{Graham Smith* and Urs D. Wermuth}

Faculty of Science and Technology, Queensland University of Technology, GPO Box 2434, Brisbane, Queensland 4001, Australia

Correspondence e-mail: g.smith@qut.edu.au

Received 23 June 2011

Accepted 11 July 2011

Online 28 July 2011

In the structure of the title 1:1 proton-transfer compound of brucine with 2-(2,4,6-trinitroanilino)benzoic acid, $\mathrm{C}_{23} \mathrm{H}_{27^{-}}$ $\mathrm{N}_{2} \mathrm{O}_{4}{ }^{+} \cdot \mathrm{C}_{13} \mathrm{H}_{7} \mathrm{~N}_{4} \mathrm{O}_{8}{ }^{-} \cdot \mathrm{H}_{2} \mathrm{O}$, the brucinium cations form classic undulating ribbon substructures through overlapping head-totail interactions, while the anions and the three related partial solvent water molecules (having occupancies of $0.73,0.17$ and $0.10)$ occupy the interstitial regions of the structure. The cations are linked to the anions directly through $\mathrm{N}-$ $\mathrm{H} \cdot \mathrm{O}_{\mathrm{COO}^{-}}$hydrogen bonds and indirectly by the three water molecules, which form similar conjoint cyclic bridging units [graph set $R_{4}^{2}(8)$ ] through $\mathrm{O}-\mathrm{H} \cdots \mathrm{O}_{\mathrm{C}=\mathrm{O}}$ and $\mathrm{O}-\mathrm{H} \cdots \mathrm{O}_{\mathrm{COO}}$ hydrogen bonds, giving a two-dimensional layered structure. Within the anion, intramolecular $\mathrm{N}-\mathrm{H} \cdots \mathrm{O}_{\mathrm{COO}^{-}}$and $\mathrm{N}-$ $\mathrm{H} \cdot \mathrm{O}_{\text {nitro }}$ hydrogen bonds result in the benzoate and picrate rings being rotated slightly out of coplanarity [inter-ring dihedral angle $\left.=32.50(14)^{\circ}\right]$. This work provides another example of the molecular selectivity of brucine in forming stable crystal structures, and also represents the first reported structure of any form of the guest compound 2-(2,4,6-trinitroanilino)benzoic acid.

\section{Comment}

Although brucine has been used largely for the resolution of certain chiral compounds (Wilen, 1972), it has proven utility in the formation of crystalline adducts and salts with achiral carboxylic acids. In particular, the benzoic acid analogues have provided a number of brucinium salt structures, many of which are solvated, e.g. benzoic acid (a trihydrate) (Białońska \& Ciunik, 2006b), 3-nitrobenzoic acid (methanol monosolvate) (Oshikawa et al., 2002), 4-nitrobenzoic acid (isomorphous dihydrate and methanol monosolvate) (Białońska \& Ciunik, 2007), 4-hydroxybenzoic acid (isopropyl alcohol monosolvate) (Sada et al., 1998), 3,5-dinitrobenzoic acid (trihydrate, methanol monosolvate and disolvate) (Białońska \& Ciunik, $2006 a$ ) and the anhydrous example with 5-nitrosalicylic acid (Smith, Wermuth, Healy \& White, 2006). Three 1:1 salts are also known, viz. with 5-nitrophthalic acid (a dihydrate) (Smith et al., 2005), isophthalic acid (a trihydrate) (Smith, Wermuth, Young \& White, 2006) and 4,5-dichlorophthalic acid (anhydrous) (Smith et al., 2007a). However, with these acids, formation is certainly a hit-or-miss process, the selectivity being dependent upon guest molecule compatibility with the interstitial cavities in the brucinium cation substructures which are present in a large number of brucine adduct and brucinium proton-transfer compounds (Gould \& Walkinshaw, 1984; Dijksma et al., 1998; Oshikawa et al., 2002; Białońska \& Ciunik, 2004; Smith, Wermuth, Healy \& White, 2006). In these substructures, the brucine species form undulating ribbons comprising overlapping head-to-tail molecules, this host structure then accomodating the compatible guest molecule or molecules and interacting with them through hydrogenbonding associations. This phenomenon accounts for the presence in many of the structures of various polar solvent molecules. It has also been noted that the two-molecule brucine repeat period will be $c a 12.5 \AA$ (the cell dimension) in the direction of a $2_{1}$ screw axis, of which there is a high incidence among the small number of space groups into which brucine and its compounds and adducts fall (Smith, Wermuth, Healy \& White, 2006).

The isomeric picraminobenzoic acids [2-, 3- and 4-(2,4,6trinitroanilino)benzoic acid] were first synthesized by the reaction of the corresponding monoaminobenzoic acid with picryl chloride in 1911 (Crocker \& Matthews, 1911). We have synthesized these three compounds using picrylsulfonic acid rather than picryl chloride, reporting the crystal structure of the para isomer (Smith et al., 2007b). However, the uncompromising crystal morphology of the ortho and meta isomers precluded the structure determinations of these. The 1:1 stoichiometric reaction of 2-(2,4,6-trinitroanilino)benzoic acid with brucine in aqueous ethanol gave good crystals of the orange-red hydrated title salt, (I), and the structure is reported here. No suitable crystals resulted from the reactions of brucine with the meta and para isomers.
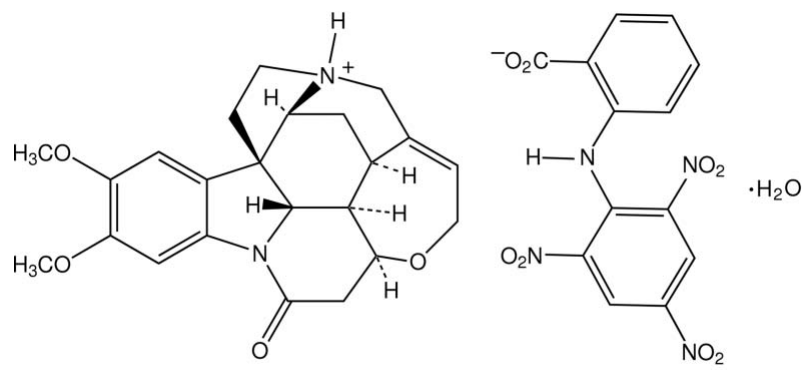

(I)

In (I), protonation has occurred, as expected, at N19 of the brucine cage (Fig. 1), the absolute configuration of the seven chiral centres of the brucinium cation being invoked (Peerdeman, 1956). These cations form the previously described undulating ribbon host substructures, which have a dimeric repeat period in (I) of 12.4407 (3) $\AA$ along the direction of 


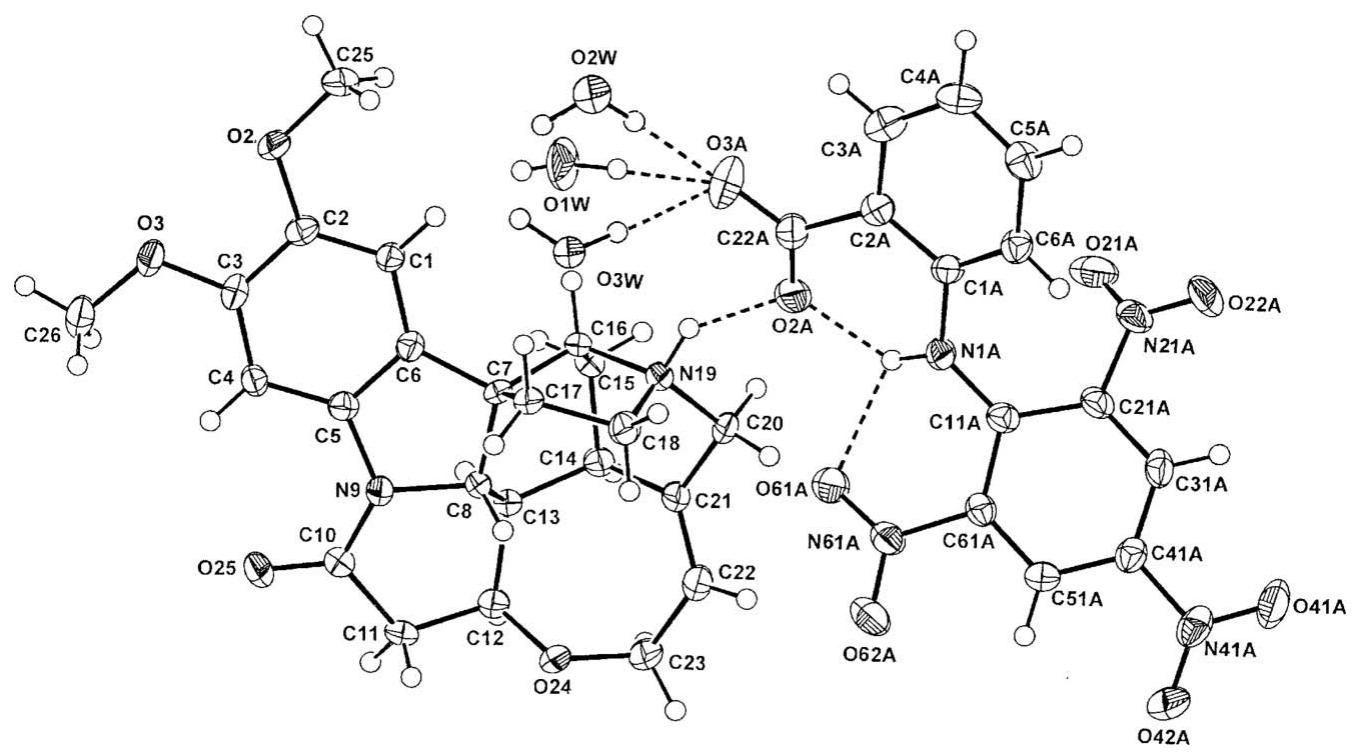

Figure 1

The molecular configuration and atom-numbering scheme for the brucinium cation, the $o$-picraminobenzoate anion and the partial solvent water molecules $(\mathrm{O} 1 \mathrm{~W}-\mathrm{O} 3 \mathrm{~W})$ in $(\mathrm{I})$. Displacement ellipsoids are drawn at the $50 \%$ probability level. Inter-species hydrogen bonds are shown as dashed lines.

propagation [a $21_{1}$ screw axis, the $a$ cell dimension] (Fig. 2). This value for the dimeric repeat in (I) is consistent with those for similarly structured brucine compounds (Gould \& Walkinshaw, 1984; Smith, Wermuth, Healy \& White, 2006). There is a molecule offset of $c a 120^{\circ}$ in the repeat unit of (I).

The monoanion and the three associated partial solvent water molecules $[\mathrm{O} 1 \mathrm{~W}$ (site-occupancy factor $=0.73$ ), $\mathrm{O} 2 \mathrm{~W}$ (site-occupancy factor $=0.17$ ) and $\mathrm{O} 3 W$ (site-occupancy factor $=0.10)$ ] occupy the interstitial volumes between the brucine substructures and are hydrogen bonded to them. The brucinium cations form an $\mathrm{N}^{+}-\mathrm{H} \cdots \mathrm{O}$ hydrogen bond with a carboxylate $\mathrm{O}$-atom acceptor of the anion, while the water

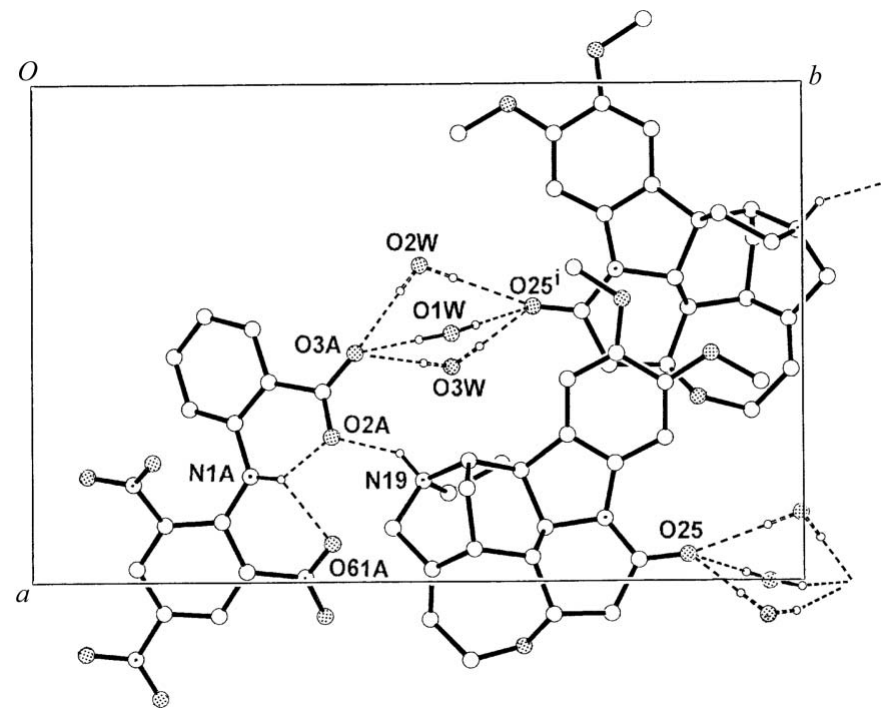

Figure 2

The cation-anion-water hydrogen-bonding environment in (I), showing the head-to-tail overlap of the brucinium cations which are part of the substructure extending along $a$. Hydrogen bonds are shown as dashed lines and non-associative $\mathrm{H}$ atoms have been omitted. [For symmetry code (i), see Table 1.] linkages are unusual, the three partial molecules forming a set of similar conjoint cyclic associations [graph set $R_{4}^{2}(8)$; see Bernstein et al. (1995) for graph-set notation] involving two $\mathrm{O}$-atom acceptor atoms (brucinium carbonyl atom O25 and carboxylate atom $\mathrm{O} 3 A$ of the anion) (Table 1) (see Fig. 2), giving a two-dimensional structure which forms layers down the $c$ cell direction (Fig. 3). Within the anion, intramolecular $\mathrm{N}-\mathrm{H} \cdots \mathrm{O}_{\mathrm{COO}^{-}}$and $\mathrm{O}-\mathrm{H} \cdots \mathrm{O}_{\text {nitro }}$ hydrogen bonds result in moderate rotation of the benzoate and picrate ring systems out of coplanarity [inter-ring dihedral angle $\left.=32.50(14)^{\circ}\right]$. The ortho-carboxylate group of the benzoate ring is rotated slightly out of the plane of the benzene ring [ $\mathrm{C} 1 A-\mathrm{C} 2 A-$ $\left.\mathrm{C} 22 A-\mathrm{O} 3 A=159.4(3)^{\circ}\right]$, while the two ortho-related nitro groups are similarly non-coplanar with the picrate ring $\left[\mathrm{C} 11 A-\mathrm{C} 21 A-\mathrm{N} 21 A-\mathrm{O} 22 A=151.7(3)^{\circ}\right.$ and $\mathrm{C} 11 A-$ $\left.\mathrm{C} 61 A-\mathrm{N} 61 A-\mathrm{O} 61 A=-165.2(3)^{\circ}\right]$. The less sterically compromised para-nitro group is essentially coplanar with the picrate ring $\left[\mathrm{C} 31 A-\mathrm{C} 41 A-\mathrm{N} 41 A-\mathrm{O} 42 A=-177.8(3)^{\circ}\right]$. One of the $\mathrm{O}$ atoms of the ortho-related nitro group at $\mathrm{C} 21 A$ is

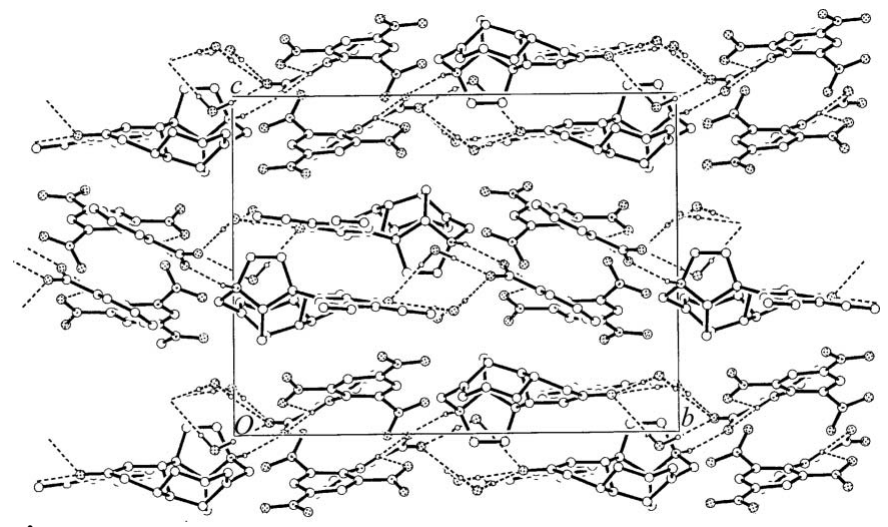

Figure 3

The layered structure of (I) in the unit cell, viewed down the $a$ cell direction. 
involved, not unexpectedly, in some short intramolecular nonbonded interactions $[\mathrm{O} 21 A \cdots \mathrm{C} 1 A=2.852$ (4) $\AA$ and $\mathrm{O} 21 A \cdots \mathrm{N} 1 A=2.892(4) \AA$ ].

The structure presented here provides another example of the molecular selectivity of brucine in forming stable complexes and is also the first reported structure of any form of the guest compound 2-(2,4,6-trinitroanilino)benzoic acid.

\section{Experimental}

Compound (I) was synthesized by heating together brucine tetrahydrate $(1 \mathrm{mmol})$ and 2-(2,4,6-trinitroanilino)benzoic acid (opicraminobenzoic acid) $(1 \mathrm{mmol})$ in ethanol-water $(1: 1 \mathrm{v} / \mathrm{v}, 50 \mathrm{ml})$ under reflux for $10 \mathrm{~min}$. After concentration to $c a 30 \mathrm{ml}$, partial room-temperature evaporation from the hot-filtered solution gave short orange-red prisms of (I) (m.p. $475 \mathrm{~K}$ ).

\section{Crystal data \\ $\mathrm{C}_{23} \mathrm{H}_{27} \mathrm{~N}_{2} \mathrm{O}_{4}{ }^{+} \cdot \mathrm{C}_{13} \mathrm{H}_{7} \mathrm{~N}_{4} \mathrm{O}_{8}{ }^{-} \cdot \mathrm{H}_{2} \mathrm{O}$ \\ $M_{r}=760.71$ \\ Orthorhombic, $P 2_{1} 2_{1} 2_{1}$ \\ $a=12.4407$ (3) § \\ $b=19.1542(5) \AA$ \\ $c=14.6744$ (4) $\AA$

$$
\begin{aligned}
& V=3496.79(16) \AA^{3} \\
& Z=4 \\
& \text { Mo } K \alpha \text { radiation } \\
& \mu=0.11 \mathrm{~mm}^{-1} \\
& T=173 \mathrm{~K} \\
& 0.35 \times 0.15 \times 0.12 \mathrm{~mm}
\end{aligned}
$$

\section{Data collection}

Oxford Gemini-S CCD areadetector diffractometer

Absorption correction: multi-scan

(CrysAlis PRO; Oxford

Diffraction, 2010)

$T_{\min }=0.911, T_{\max }=0.980$

\section{Refinement}

$R\left[F^{2}>2 \sigma\left(F^{2}\right)\right]=0.043$

$w R\left(F^{2}\right)=0.109$

$S=0.96$

4487 reflections

$$
\begin{aligned}
& 12634 \text { measured reflections } \\
& 4487 \text { independent reflections } \\
& 3291 \text { reflections with } I>2 \sigma(I) \\
& R_{\text {int }}=0.031
\end{aligned}
$$

A nonstandard orthorhombic axial setting was chosen for a better comparison with previous similar brucine structures. C-bound $\mathrm{H}$ atoms were included at calculated positions, with $\mathrm{C}-\mathrm{H}=0.93$ (aromatic and $s p^{2}$ ) or $0.96-0.98 \AA$ (aliphatic), and treated as riding, with $U_{\text {iso }}(\mathrm{H})=1.2 U_{\text {eq }}(\mathrm{C})$. The $\mathrm{H}$ atom of the brucinium $\mathrm{N}^{+}-\mathrm{H}$ group was located in a difference Fourier synthesis and its positional and isotropic displacement parameters were allowed to ride in the refinement $\left[U_{\text {iso }}(\mathrm{H})=1.2 U_{\text {eq }}(\mathrm{N})\right]$. The occupancies of the three partial solvent water molecules were determined as $0.73(\mathrm{O} 1 W), 0.17$ $(\mathrm{O} 2 W)$ and $0.10(\mathrm{O} 3 W)$ from peak heights, and the $\mathrm{O}$ atoms of the two minor-occupancy components were refined isotropically. All three partial water molecules were found to be associated with the same two $\mathrm{O}$-atom acceptors, and the $\mathrm{H}$ atoms on these were derived geometrically and also allowed to ride in the refinement $\left[U_{\text {iso }}(\mathrm{H})=\right.$ $\left.1.2 U_{\text {eq }}(\mathrm{O})\right]$. The known absolute configuration of the parent strychnidin-10-one molecule (Peerdeman, 1956) was invoked and Friedel pairs were averaged for data used in the final cycles of refinement.

Data collection: CrysAlis PRO (Oxford Diffraction, 2010); cell refinement: CrysAlis PRO; data reduction: CrysAlis PRO; program(s) used to solve structure: SIR92 (Altomare et al., 1994);
Table 1

Hydrogen-bond geometry $\left(\AA,^{\circ}\right)$.

\begin{tabular}{lllll}
\hline$D-\mathrm{H} \cdots A$ & $D-\mathrm{H}$ & $\mathrm{H} \cdots A$ & $D \cdots A$ & $D-\mathrm{H} \cdots A$ \\
\hline $\mathrm{N} 19-\mathrm{H} 19 \cdots \mathrm{O} 2 A$ & 0.91 & 1.94 & $2.708(4)$ & 141 \\
$\mathrm{~N} 1 A-\mathrm{H} 1 A \cdots \mathrm{O} 2 A$ & 0.90 & 1.90 & $2.662(3)$ & 141 \\
$\mathrm{~N} 1 A-\mathrm{H} 1 A \cdots \mathrm{O} 2 A$ & 0.90 & 2.10 & $2.653(4)$ & 118 \\
$\mathrm{O} 1 W-\mathrm{H} 11 W \cdots \mathrm{O} 3 A$ & 0.89 & 1.80 & $2.695(4)$ & 177 \\
$\mathrm{O} 1 W-\mathrm{H} 12 W \cdots \mathrm{O} 25^{\mathrm{i}}$ & 0.90 & 2.19 & $3.091(4)$ & 178 \\
$\mathrm{O} 2 W-\mathrm{H} 21 W \cdots \mathrm{O} 3 A$ & 0.91 & 2.17 & $3.079(14)$ & 179 \\
$\mathrm{O} 2 W-\mathrm{H} 22 W \cdots \mathrm{O} 25^{\mathrm{i}}$ & 0.91 & 2.11 & $3.020(14)$ & 179 \\
$\mathrm{O} 3 W-\mathrm{H} 31 W \cdots \mathrm{O} 3 A$ & 0.90 & 2.17 & $3.08(2)$ & 179 \\
$\mathrm{O} 3 W-\mathrm{H} 32 W \cdots \mathrm{O} 25^{\mathrm{i}}$ & 0.91 & 1.73 & $2.65(2)$ & 179 \\
\hline
\end{tabular}

Symmetry code: (i) $x-\frac{1}{2},-y+\frac{3}{2},-z$.

program(s) used to refine structure: SHELXL97 (Sheldrick, 2008) within WinGX (Farrugia, 1999); molecular graphics: PLATON (Spek, 2009); software used to prepare material for publication: PLATON.

The authors acknowledge financial support from the Australian Research Grants Committee and from the Faculty of Science and Technology, Queensland University of Technology.

Supplementary data for this paper are available from the IUCr electronic archives (Reference: FG3225). Services for accessing these data are described at the back of the journal.

\section{References}

Altomare, A., Cascarano, G., Giacovazzo, C., Guagliardi, A., Burla, M. C., Polidori, G. \& Camalli, M. (1994). J. Appl. Cryst. 27, 435.

Bernstein, J., Davis, R. E., Shimoni, L. \& Chang, N.-L. (1995). Angew. Chem. Int. Ed. Engl. 34, 1555-1573.

Białońska, A. \& Ciunik, Z. (2004). CrystEngComm, 6, 276-279.

Białońska, A. \& Ciunik, Z. (2006a). Acta Cryst. C62, o450-o453.

Białońska, A. \& Ciunik, Z. (2006b). Acta Cryst. E62, o5817-o5819.

Białońska, A. \& Ciunik, Z. (2007). Acta Cryst. C63, o120-o122.

Crocker, J. C. \& Matthews, F. (1911). J. Chem. Soc. Trans. 99, 301-313.

Dijksma, F. J. J., Gould, R. O., Parsons, S., Taylor, P. \& Walkinshaw, M. D. (1998). Chem. Commun. pp. 745-746.

Farrugia, L. J. (1999). J. Appl. Cryst. 32, 837-838.

Gould, R. O. \& Walkinshaw, M. D. (1984). J. Am. Chem. Soc. 106, 78407842.

Oshikawa, T., Pochamroen, S., Takai, N., Ide, N., Takemoto, T. \& Yamashita, M. (2002). Heterocycl. Commun. 8, 271-274.

Oxford Diffraction (2010). CrysAlis PRO. Oxford Diffraction Ltd, Yarnton, England.

Peerdeman, A. F. (1956). Acta Cryst. 9, 824.

Sada, K., Yoshikawa, K. \& Miyata, M. (1998). Chem. Commun. pp. 1763-1764. Sheldrick, G. M. (2008). Acta Cryst. A64, 112-122.

Smith, G., Wermuth, U. D., Healy, P. C. \& White, J. M. (2006). Aust. J. Chem. 59, 320-328.

Smith, G., Wermuth, U. D. \& White, J. M. (2007a). Acta Cryst. E63, o4276o4277.

Smith, G., Wermuth, U. D. \& White, J. M. (2007b). Acta Cryst. E63, o4803.

Smith, G., Wermuth, U. D., Young, D. J. \& Healy, P. C. (2005). Acta Cryst. E61, o2008-o2011.

Smith, G., Wermuth, U. D., Young, D. J. \& White, J. M. (2006). Acta Cryst. E62, o1553-o1555.

Spek, A. L. (2009). Acta Cryst. D65, 148-155.

Wilen, S. H. (1972). Tables of Resolving Agents and Optical Resolutions, edited by E. L. Eliel, pp. 68-75. London: University of Notre Dame Press. 